\title{
Serum retinol concentration in patients with acute falciparum malaria in Aligarh, India
}

\author{
Adil Raza ${ }^{1}$, Haris M. Khan ${ }^{1}$, Mohd. Ashraf Malik², Abbas Ali Mahdi ${ }^{3}$, Mohd. Shahid ${ }^{1}$, Fatima \\ Shujatullah ${ }^{1}$
}

${ }^{1}$ Department of Microbiology, J.N. Medical College \& Hospital, AMU, Aligarh-202002, UP, India

${ }^{2}$ Department of Paediatrics, J.N. Medical College \& Hospital, AMU, Aligarh-202002, UP, India

${ }^{3}$ Department of Biochemistry, King George Medical University, Lucknow, UP, India

\begin{abstract}
Background: Vitamin A (retinol)-deficiency and falciparum malaria are two major public health problems in developing countries. Falciparum malaria is associated with significant destruction of erythrocytes and can lead to severe anaemia.

Methodology: The present study was designed to estimate the serum retinol concentration in 150 acute falciparum-malaria patients (aged two to five years) by High Performance Liquid Chromatography (HPLC). Serum retinol concentrations of 20 healthy (age and sex matched, population based) volunteers were included as controls.

Results: The mean serum retinol concentration of healthy controls was $34.31 \pm 1.274 \mu \mathrm{g} / \mathrm{dl}$ and that of diseased cohort was $12.562 \pm 0.276$ $\mu \mathrm{g} / \mathrm{dl}$. The mean parasitemia was $1239.2 \pm 33.609$ per $\mu \mathrm{L}$.

Conclusions: The diseased cohort demonstrated significant reduction in concentrations of retinol in comparison to healthy controls ( $\mathrm{p}<$ 0.001 ) and there was an inverse relationship (coefficient of correlation $r=-0.899$ ) between parasitemia and serum retinol concentration.
\end{abstract}

Key words: falciparum- malaria, serum retinol, parasitemia, India

J Infect Dev Ctries 2009; 3(11):865-868.

(Received 8 June 2009 - Accepted 24 October 2009)

Copyright $\odot 2009$ Shahid et al. This is an open-access article distributed under the Creative Commons Attribution License, which permits unrestricted use, distribution, and reproduction in any medium, provided the original work is properly cited.

\section{Introduction}

Malaria, which is a disease of antiquity, has proved to be a formidable deterrent to the cultural and socioeconomic progress of mankind throughout the globe especially in the tropical, subtropical and monsoon prone regions. Malaria imposes great socioeconomic burden on humanity and with six other diseases (diarrhoea, HIV/AIDS, tuberculosis, measles, hepatitis-B, and pneumonia) accounts for $85 \%$ of the global infectious disease burden $[1,2]$. Malaria afflicts more than 90 countries and territories in the tropical and subtropical regions and almost one half of them are in Africa, South of Sahara. About $36 \%$ of the world population (i.e. 2020 million) is exposed to the risk of contacting malaria. The World Health Organization (WHO) estimates 300-500 million malaria cases annually, with $90 \%$ of this burden in Africa [3]. In addition, the estimated annual mortality attributed to malaria ranges from 0.7 to 2.7 million globally and more than $75 \%$ of the total morbidity occurs in children and expectant mothers [4,5]. According to the $\mathrm{WHO}$, out of approximately
1.4 billion people living in 11 countries in the southeastern Asian region, 1.2 billion are at risk of contracting malaria, the majority of whom are from India [3,6], and Southeast Asia contributed $76 \%$ of the total cases.

In India, most cases of malaria occur in Orissa state. Although Orissa has a population of 36.7 million (3.5\% of India), it contributed $25 \%$ of a total of 1.5-2.0 million reported malaria cases annually, $39.5 \%$ of Plasmodium falciparum malaria, and $30 \%$ of deaths caused by malaria in India. Utter Pradesh (UP), India's largest state, contributes only $5 \%$ of total cases [7].

Vitamin A deficiency is associated with common childhood diseases and poor immune function [8], and poses a higher risk for childhood mortality [9]. Moreover the importance of vitamin A to the health and visual acuity in children has been known since the 1920s [10]. Children aged one to three years are affected more due to the fast rate of growth and higher physiological requirement of vitamin $\mathrm{A}$ at that age [11]. 
Table 1. Serum retinol concentrations ${ }^{*}$ versus parasitemia in the study population.

\begin{tabular}{|c|c|c|c|}
\hline \multirow{2}{*}{ Parasitemia per $\mu \mathrm{L}$} & \multicolumn{2}{|c|}{ Serum retinol concentration $\mu \mathrm{g} / \mathrm{dl}$} & \multirow{2}{*}{ No. of patients $\mathrm{N}=150$} \\
\cline { 2 - 3 } & Range & Mean $\pm \mathrm{SE}$ & 26 \\
\hline $600-800$ & $13.33-21.33$ & $16.69 \pm 0.441$ & 38 \\
\hline $801-1000$ & $12.09-20.13$ & $14.95 \pm 0.279$ & 16 \\
\hline $1001-1200$ & $12.03-14.35$ & $13.33 \pm 0.312$ & 35 \\
\hline $1201-1400$ & $8.03-14.08$ & $12.09 \pm 0.336$ & 8 \\
\hline $1401-1600$ & $8.38-12.87$ & $10.25 \pm 0.117$ & 16 \\
\hline $1601-1800$ & $7.03-13.23$ & $8.99 \pm 0.769$ & 3 \\
\hline $1801-2000$ & $7.03-8.98$ & $8.23 \pm 0.151$ & \\
\hline
\end{tabular}

$*$ Serum retinol concentration in healthy volunteers $=34.31 \pm 1.274 \mu \mathrm{g} / \mathrm{dl}$.

There are few reports indicating the decrease in serum retinol concentration during malarial infection and also the relation of retinol concentration with $P$. falciparum parasitemia [12,13, 14]. Moreover, such studies are lacking from the Indian subcontinent even though India contributes a major percent of $P$. falciparum infections. Therefore, the present preliminary study was designed to analyze the serum retinol concentration in $P$. falciparum infected patients, and to analyze the relation of serum retinol concentration with $P$. falciparum parasitemia.

\section{Materials and methods}

Study population

The study was conducted in confirmed patients of $P$. falciparum infection who attended out-patient clinics or those admitted to the wards of $\mathrm{J} \mathrm{N}$ Medical College and Hospital, AMU, Aligarh, India, during May 2006 to September 2007. The study population was comprised of 150 children with the age range of two to five years. Twenty age and sex matched, population-based healthy volunteers were also included as controls. There were no ocular signs and symptoms of vitamin A deficiency and night blindness in healthy controls.

Thick and thin Giemsa-stained blood films were screened for the presence of Plasmodium species. The parasite count (parasites/ $\mu \mathrm{L}$ ) was done by counting 200 white blood cells and the number expressed on the basis of $8,000 \mathrm{WBC} / \mu \mathrm{L}[15,16]$.

\section{Calculation of parasitemia}

\section{$=\frac{\text { no.of parasites seen }}{\text { no.of leucocytes seen }} \times 8000$}

\section{Serum samples}

Venous blood was collected aseptically from the patients and was kept in a dark environment for less than 6 hours before centrifugation. Serum was obtained by centrifugation at $1,500 \times \mathrm{g}$ for 5 minutes at room temperature, and aliquots were prepared and immediately stored at $-70^{\circ} \mathrm{C}$ until processed further.

Vitamin A was measured by high-performance liquid chromatography (HPLC) per the method of Omu et al. [17]. Briefly, $\alpha$-tocopherol acetate and retinol acetate was pipetted into Eppendorf tubes. Respective serum was added to the tubes and vortex. Hexane extract of vitamin A was aspirated in a glass tube, dried under nitrogen stream, and dissolved into methanol. Finally, this preparation was injected into HPLC fitted with a reverse phase C-18 stainless steel column. The vitamin was eluted with methanol at the flow rate of $1.5 \mathrm{ml} / \mathrm{min}$ for 15 minutes. The peak heights and the curve areas of vitamin $\mathrm{A}$ and its acetate were measured to calculate the amount of vitamin A in plasma in an ultraviolet detector using 292-nm filters.

\section{Statistical analysis}

Statistical analysis was done using SPSS, version 14, Statistics software. Unpaired Student's t was applied for the comparison of serum vitamin A levels of cases with those of controls, and a $p$ value of $<0.001$ was regarded as significant. Descriptive statistics including mean, SDs and SEs were calculated for each continuous variable. Pearson correlation analyses were performed to determine the degree and direction of association between two variables (parasitemia and serum vitamin A concentration). 


\section{Results}

In this study the mean serum vitamin A level in the patient-cohort was $12.50 \pm 0.276 \mu \mathrm{g} / \mathrm{dL}$ against the mean value of $34.311 \pm 1.274 \mu \mathrm{g} / \mathrm{dL}$ in healthy controls and it was found statistically significant $(\mathrm{p}<$ 0.001 ). Moreover, there was a gradual fall in serum vitamin A level as the parasitemia increased (Table 1 and Figure 1). The Pearson coefficient of the correlation between parasitemia with serum vitamin A was -0.899, which demonstrates an inverse relationship. Figure 1 shows the correlation between parasitemia and serum vitamin A concentration.

\section{Discussion}

Interestingly, in this study, a gradual fall in serum retinol concentration was observed as the parasitemia increased. In a previous study by Das et al. [14], that involved cases of severe and mild malaria, a similar reduction of serum retinol concentration was reported. The serum concentration of retinol, the alcohol form of vitamin A, decreases during malarial infections. The reduction has been characterized as a direct consequence of the inflammatory response to Plasmodium infection $[12,13]$. Increased release of interleukin- 6 causes a reduction in the serum level of retinol binding proteins and pre-albumin, impeding the transport of vitamin A from the liver to the target tissues [13].

Malnutrition is one of the leading causes of childhood morbidity and mortality worldwide. In developing countries, $15 \%$ or more of children born each year die before they reach the age of 5 years, mainly due to malnutrition, parasitic infections and low birth weight. Malaria has been shown to impair growth of younger but not older children [18].

Beneficial protective effects of vitamin A or zinc on malaria-related morbidity have been demonstrated in Papua New Guinea, Peru and Zanzabari [19-21]. Two randomised, controlled trials conducted in Ghana did not find an overall significant effect of vitamin A on malaria parasitemia rates or parasite densities although the studies showed a reduction of $23 \%$ and $32 \%$ of probable malaria illness in supplemented children [22]. However, the number of children with probable malaria was so small that this study lacked adequate power to demonstrate an effect of vitamin A on slideconfirmed malaria morbidity.

In a randomised control trial in Burkina Faso done in 148 children (6 months to 6 years), by administering a single dose of vitamin A $(200,000$ IU) with a daily zinc supplementation, a $30 \%$ reduction in slide confirmed malaria fever were reported [23]. A recent population based study [24] evaluated the of impact of vaccine, use of insecticide treated bed nets, intermittent presumptive or preventive therapy in infants (IPTi) and the impact of vitamin A supplementation on the malaria morbidity and reported similar views of reduced malaria morbidity with vitamin A supplementation.

Another study done in Papua New Guinea (children aged 6 to 60 months were supplemented with vitamin A) showed that the highest morbidity rates due to $P$. falciparum infection were in the age group of 12 to 36 months when the immune system is actively developing. Lesser effects were seen in the 37- to 60-age group in which some degree of protection might have already developed. Furthermore, the number of episodes of fever with parasitemia was $30 \%$ lower in the vitamin A supplemented group, and while vitamin A supplementation reduced the morbidity in the cases of falciparum malaria, there was no effect on the incidence of falciparum malaria. [25].

It has been demonstrated that free retinol has a pharmacological effect against malarial parasites [26], but the low concentration of free retinol in the serum make its hypothetical effect inconclusive [27]. Therefore, based on the present study and those discussed above, we conclude that reduced retinol concentrations are associated with $P$. falciparum malaria, and that vitamin A supplementation might help reduce malaria morbidity.

\section{References}

1. Murray CJL, Lopez AD (1996) Evidence-based health policy lessons from the Global Burden of Disease Study. Science 274: 740-743.

2. Murray CJL, Lopez AD (1999) The Global Burden of Disease 1990-2020: alternative projections of mortality and disability by cause for eight regions. Lancet 349: 14981504.

3. Kumar A, Valecha N, Jain T, Dash AP (2007) Burden of Malaria in India: Retrospective and Prospective View. Am J Trop Med Hyg 77 (Suppl6): 69-78.

4. Bremen JG (2001) The ears of the hippopotamus: manifestations, determinants and estimation of the malaria burden. Am J Trop Med Hyg 64 (Suppl 1): 1-11.

5. Snow RW, Guerra CA, Noor AM, Myint HY, Hay SI (2005) The global distribution of clinical episodes of Plasmodium falciparum malaria. Nature 434: 214-217.

6. Kondrachine AV (1992) Malaria in WHO Southeast Asia Region. Indian J Malariol 29: 129-160.

7. NVBDCP, Drug Resistance Status in India: An Update 2002. Delhi: Directorate of National Vector Borne Disease Control Programme. 
8. Sema R et al. (1993) Abnormal T-cell subset proportions in vitamin A deficient children. Lancet 431: 5-8.

9. Somer A et al. (1986) Impact of vitamin A supplementation on childhood mortality: a randomised controlled community trial. Lancet: 1169-1173.

10. Wolbach SB, Howe PR (1925) Tissue changes following deprivation of fat-soluble vitamin A. J of experimental Med 42: 753-777.

11. Oomen HAPC (1957) The incidence of xerophthalmia in Java in relation to age and sex. Doc Med Georgr Trop 9: 357-368.

12. Thurnham DI, Singkamani R (1991) The acute phase response and vitamin A status in malaria. Trans R Soc Trop Med Hyg 85: 194-199.

13. Tabone MD, Muanza K, Lyagoubi M, Jardel C, Pied S, Amedee-Manesme O(1992) The role of interleukin-6 in vitamin A deficiency during Plasmodium falciparum malaria and possible consequences for vitamin A supplementation. Immunology 75: 553-554.

14. Das BS, Thurnham DI, Das BD (1996) Plasma $\alpha$-tocopherol, retinol, and carotenoids in children with falciparum malaria. Am J Clin Nutr 64: 94-100.

15. Trape JF (1985) Rapid evaluation of malaria parasite density and standardization of thick smear examination for epidemiological investigations. Trans R Soc Troop Med Hyg 79: 181-184.

16. WHO. Basic laboratory methods in medical parasitology (1991) Special techniques for plasmodia. WHO Geneva pp. 48.

17. Omu AE, Fatinikun T, Mannazhath N, Abraham S (1999) Significance of simultaneous determination of serum and seminal plasma $\alpha$-tocopherol and retinol in infertile men by high-performance liquid chromatography. Andrologia 31: 347-354.

18. McGregor IA, Gilles HM. Walters JH, Devis AH, Pearson and FA (1956) Effects of heavy and repeated malarial infections on Gambian infants and children. Br Med J1 2: 686-692.

19. Richard SA, Zavaleta N, Caulifield LE, Black RE, Witzig RS, Shankar AH (2006) Zinc and iron supplementation and malaria, diarrhoea, and respiratory infections in children in the Peruvian Amezon. Am J Troop Med Hyg 75: 126-132.

20. Shankar AH, Genton B, Semba RD, Baisor M, Paino J, Tamja S, Adiguma T, Wu L, Rare L, Bannon D, Tielsch JM, West KP Jr, Alpers MP. The influence of zinc supplementation on morbidity due to Plasmodium falciparum: a randomised trial in preschool children in
Papua New Guinea (2000) Am J Troop Med Hyg 62: 663669.

21. Cusick SE, Tielsch JM, Ramsan M, Jape JK, Sazawal S, Black RE, Stoltzfus RJ (2005) Short term effects of vitamin A and antimalarial treatment on erythropoiesis in severely anemic Zanzibari preschool children. Am J Clin Nutr 82: 406-412.

22. Binka F, Ross F, Morris S (1995) Vitamin A supplementation and childhood malaria in Northern Ghana. Am J Clin Nutr 61: 853-859.

23. Sanjoaquin MA, Molyneux ME (2009) Malaria and vitamin A deficiency in African children: a vicious circle? Malaria Journal 8: 134-139.

24. Moorthy VS, Reed Z, Smith PG (2009) Clinical trials to estimate the efficacy of preventive interventions against malaria in paediadric populations: a methodological review. Malaria Journal 8: 23-30.

25. Shankar AH,Genton B, Semba DR, Baisor M, Paino J, Tamja S, Adiguma T, Wu L, Rare L, Tielsch JM, Alpers MP, West Jr KP (1999) Effect of vitamin A supplementation on mobidity due to Plasmodium falciparum in young children in Papua New Guinea: a randomised trial. Lancet 354: 203-209.

26. Davis T, Skinner-Adams T, Beilby J (1998) In vivo growth inhibition of Plasmodium falciparum by retinol at concentration present in normal human serum. Acta Tropica 69: 111-119.

27. Ross AC (1993) Overview of retinoid metabolism. J Nutr 123: $346-350$.

\section{Corresponding Author}

Dr. Mohd. Shahid

Department of Microbiology

Jawaharlal Nehru Medical College A. M. U., Aligarh, U.P. India

Phone: 009411802526

Fax: +91-571-2721776

E-mail: shahidsahar@yahoo.co.in

drmohdshahid123@yahoo.com

Conflict of Interest: No conflict of interest is declared. 